\title{
Relacionamento colaborativo no canal de distribuição: uma matriz para análise
}

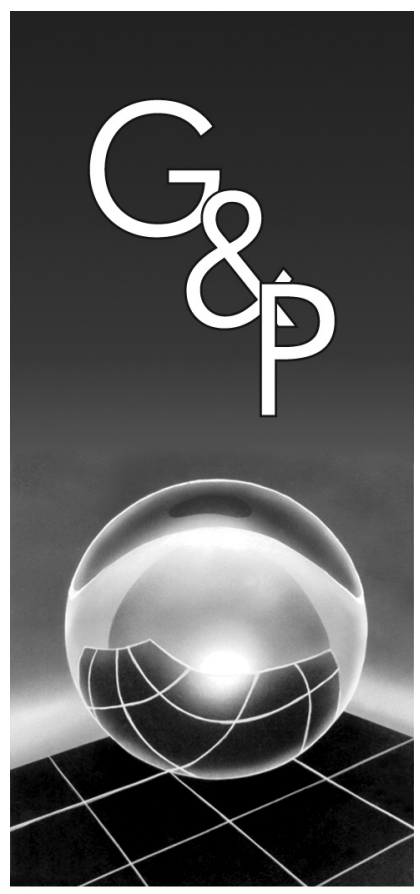

\author{
Gessuir Pigatto \\ Rosane Lucia Chicarelli Alcantara
}

\section{Resumo}

Em um mercado cada vez mais dinâmico e turbulento, a habilidade de uma empresa em desenvolver e administrar, com sucesso, seus relacionamentos com outras empresas vem se tornando uma competência necessária que, se bem desenvolvida, pode vir a ser uma fonte de vantagem competitiva sustentável. Neste contexto, fornecedores buscam se adaptar ao aumento do poder de grandes redes varejistas, ao crescimento das centrais de compras, ao fortalecimento das lojas independentes e de demais formatos nos canais de distribuição. Entretanto, essas empresas ainda possuem dificuldade em acompanhar e avaliar os relacionamentos comerciais e, conseqüentemente em adaptá-los a essa nova situação. Assim, o objetivo deste artigo é propor uma matriz de análise que possa avaliar o tipo de relacionamento existente entre agentes comerciais, por meio do acompanhamento dos comportamentos e das ações desenvolvidas por essas empresas. A partir de uma ampla revisão teórica, foram identificadas variáveis presentes em relacionamentos comerciais, como por exemplo, a confiança, o comprometimento, a interdependência, a cooperação, bem como ações e comportamentos que se relacionam ou estão associados a cada uma dessas variáveis. Partindo do pressuposto que a presença de uma ou mais das variáveis em questão sinaliza a possibilidade da existência de diferentes padrões de arranjos entre as empresas, desde o oportunista até o totalmente colaborativo e, utilizando as ações e comportamentos para determinar essa ocorrência, elaborou-se a matriz em questão. Ela é composta por 4 categorias que podem ser utilizadas para classificar o tipo de relacionamento existente entre dois agentes comerciais, dentro de 4 niveis estabelecidos: comportamento tradicional, comportamentos colaborativos, ações colaborativas, e relacionamento colaborativo. Após o desenvolvimento teórico da matriz, optou-se por um teste inicial junto a 10 pares de empresas, redes supermercadistas localizadas no interior do Estado de São Paulo e um de seus fornecedores. $O$ resultado obtido sinaliza ser possível, por meio da avaliação dos comportamentos e das ações dos parceiros, determinar o tipo de relacionamento existente entre os pares estudados, auxiliando as empresas na definição de estratégias objetivando aprimorar esta relação ou encerrá-la, se for o caso.

Palavras-chave: Matriz de análise. Avaliação de relacionamentos. Canais de distribuição.

\section{Introdução}

Nos atuais canais de distribuição, os participantes são os mesmos dos canais tradicionais, mas as regras do jogo mudaram e os papéis e as responsabilidades de cada membro não são mais baseados em funções tradicionais (comprar, vender ou entregar um produto), mas sim em responsabilidades (a empresa com melhor desempenho na execução de determinada tarefa torna-se responsável por ela). Dessa forma, por exemplo, o fornecedor pode se tornar responsável pelo layout de um determinado espaço dentro da loja de um distribuidor. Ao contrário dos canais tradicionais, os papéis e as responsabilidades dos participantes tornaram-se fluidos, dinâmicos e voltados para o consumidor (BLACKWELL, 2001). Como conseqüência disso, as relações comerciais entre essas empresas estão se modificando, esta reestruturação está se tornando parte integrante das suas estratégias operacionais, e está resultando em relações mais próximas nas quais, em muitos casos, fica difícil saber onde começa uma empresa e termina outra (WILSON, 1995; SPEKMAN et al., 1997; COUGHLAN et al., 2002).

Assim, estar inserido em um canal de distribuição é de fundamental importância competitiva para as empresas atuais, tornando-se parte da estratégia adotada. Portanto, ações estratégicas e táticas, assim como objetivos comuns, devem ser compartilhadas, dentro de uma perspectiva global de negócios, junto às demais empresas envolvidas 
no canal. Chen e Paulraj (2004) enfatizam ainda a necessidade do desenvolvimento "da vantagem colaborativa", ao contrário "da vantagem competitiva", na construção dos atuais relacionamentos entre empresas.

Para que se possa construir uma vantagem colaborativa, é necessário entender como se relacionam os agentes comerciais inseridos em um canal de distribuição e identificar como esses agentes avaliam seus relacionamentos comerciais. Ou seja, a busca de novos padrões de relacionamento entre as empresas, cria a necessidade de parâmetros de avaliação que sinalizem se a evolução desses arranjos está trazendo os resultados desejados pelas partes. Parâmetros esses não apenas financeiros, mas que mostrem também a existência de uma maior aproximação entre as empresas envolvidas.

A revisão da literatura destaca em maior grau algumas variáveis que podem ser empregadas em estudos de relacionamento, como a confiança, o comprometimento, a interdependência, o poder, a cooperação, a comunicação, a adaptação, vínculos sociais, e, envolvimento, entre outros (DWYER et al., 1987; WILSON, 1995; KUMAR, 1996; WILSON; VLOSKY, 1997; SPEKMAN et al., 1997; LINDGREEN, 2001). A presença de uma ou mais dessas variáveis mostra a possibilidade da existência de diferentes padrões de arranjos, dentro de um continuun de relacionamento, que vai desde um relacionamento baseado apenas no oportunismo, até um relacionamento totalmente colaborativo.

Dessa forma, o artigo tem como objetivo principal apresentar uma proposta de matriz de análise que possa classificar o tipo de relacionamento existente entre dois agentes comerciais, dentro de 4 níveis estabelecidos a saber: relacionamento tradicional, comportamentos colaborativos, ações colaborativas, e relacionamento colaborativo. Esses quatro níveis estão inseridos em uma matriz $2 \times 2$, formada por um eixo que define as ações desenvolvidas pelos parceiros, e outro eixo que define os comportamentos adotados pelos mesmos parceiros comerciais. Além do objetivo principal, este artigo possui também os seguintes objetivos secundários: a) determinar a existência ou não de variáveis que possam ser empregadas na análise de relacionamentos comerciais; e b) classificá-las dentro de um índice que permita a construção da matriz de análise. Com os resultados obtidos, acredita-se ser possível avaliar as relações comerciais existentes entre as empresas, auxiliando na definição de estratégias e/ou ações a serem realizadas objetivando aprimorar esta relação ou, se for o caso, encerrar esse arranjo e buscar novos parceiros dentro da estratégia adotada.

Como forma de testar a matriz de análise, foram analisados 10 relacionamentos comerciais, formados por redes supermercadistas de pequeno e médio porte, localizados no interior do Estado de São Paulo, e 1 de seus fornecedores da indústria de mercearia básica. A escolha desse setor da economia para testar a matriz, deve-se principalmente a alguns fatores: 1 ) o setor supermercadista representa 5,5\% do PIB brasileiro, com um faturamento, em valores nominais, de $\mathrm{R} \$ 97,7$ bilhões de reais, empregando cerca de 790 mil trabalhadores em quase 72 mil lojas distribuídas por todo o País; 2) o acirramento da concorrência no auto-serviço que leva essas empresas a buscarem um diferencial competitivo diante dos concorrentes; 3) com o crescimento das vendas, decorrente da estabilização monetária e da localização privilegiada diante do consumidor, as redes supermercadistas de pequeno e médio porte estão se tornando um canal de distribuição alternativo e atraente para as indústrias; e 4) a criação de parcerias entre empresas no canal de distribuição, à medida que agiliza o fluxo de informações, pode permitir o desenvolvimento de produtos e serviços mais adequados às necessidades do cliente (SOUZA, 2005).

\section{Negociação no canal de distribuição}

A relação entre a rede varejista (distribuidor) e a indústria (fornecedor) é bastante complexa, havendo simultaneamente interesses comuns e uma série de conflitos. É consenso que esses agentes são parceiros no objetivo de disponibilizar a mercadoria para o consumidor final e, para isso, é necessário que exista uma negociação transparente entre os dois lados. Entretanto, as empresas não podem deixar de lado seus objetivos individuais, ou seja, resultados operacionais positivos que as mantenham competitivas e no mercado.

Fornecedores e distribuidores estão constantemente realizando operações comerciais. Essas operações tradicionalmente se transformam em benefícios imediatos para um dos agentes envolvidos (por exemplo, o distribuidor) e, conseqüentemente, em desvantagens para o outro agente (por exemplo, o fornecedor), de acordo com seu poder de negociação ou da situação em que a operação ocorre. Assim, negociações agressivas, em que um dos lados acaba assumindo uma posição mais intransigente, objetivando tirar proveito de uma conjuntura momentânea, pode se transformar em dificuldades futuras quando este mesmo lado necessitar de ajuda do seu parceiro. Esse tipo de operação caracteriza um contrato clássico do mercado, no qual os acordos não prevêem compartilhamento (de risco, experiência, etc.); não existe distinção nem continuidade; os agentes são intercambiáveis, lidando uns com os outros de maneira completamente independente e impessoal; negociam cada transação como se fosse a única; e começam e terminam suas transações com base somente nos méritos correntes do conjunto de ofertas (COUGHLAN et al., 2002). 
Além da relação muitas vezes conflituosa, entre distribuidores e fornecedores, outras circunstâncias levam os agentes a uma adaptação da sua forma de negociar. A tecnologia e o aumento da concorrência, por exemplo, estão alterando as formas de atuação e o crescimento das empresas, ao mesmo tempo que criam, para o consumidor final, novas formas de obter o produto desejado. Essa adaptação passa necessariamente pelo gerenciamento e trabalho colaborativo entre as empresas, acentuando a necessidade de maior entrosamento.

Buscando fortalecer os objetivos comuns, sem prejudicar os seus objetivos individuais, as empresas estão substituindo a ênfase na otimização de uma única transação, na qual o ganho de um dos lados leva à perda do outro e torna as empresas mais adversárias do que colaboradoras por estratégias que têm como objetivo a busca por transações repetitivas, com o objetivo de obtenção de eficiência e eficácia a longo prazo (GADDE; HAKANSSON, 2001). Assim, em um ambiente em que o mercado é cada vez mais dinâmico e turbulento, a habilidade de uma empresa em desenvolver e controlar com sucesso seus relacionamentos com outras empresas emerge como uma competência e uma possível fonte de vantagem competitiva sustentável (BATT, 2003).

Com isso, a maioria das empresas esta sendo forçada a redesenhar seu canal de distribuição, com as relações de sociedade entre os agentes substituindo as convencionais estruturas de livre mercado. Isso faz com que se estabeleça um novo paradigma de gestão empresarial baseado no fato de que as empresas não mais competem apenas entre si de forma isolada ou individual, mas sim por meio dos diversos canais de distribuição nos quais estão inseridas. Ritter et al. (2004) reconhecem que as empresas fazem parte de uma rede de relacionamentos, sejam relacionamentos de negócios ou não, em que ambos podem capacitar e/ou restringir o desempenho da empresa. Dessa forma, para que os produtos cheguem ao consumidor final, é necessário que haja uma interação entre o primeiro fornecedor (indústria de insumos ou agricultor) e os elos existentes entre ela e o consumidor final. Fornecedor e distribuidor precisam do consumidor final e, por maior que seja o poder exercido por uma das partes, a dependência é mútua.

Empresas que conseguem visualizar essa dependência de forma clara desenvolvem relações comerciais que lhes garantam condições privilegiadas para a evolução de seus negócios. Os relacionamentos entre distribuidor e fornecedor, em muitos setores industriais, sofrem dependências severas das operações das empresas parceiras no mercado. Dependências estas que conduzem à necessidade da cooperação e da coordenação entre as operações das empresas, a fim de se alcançar objetivos internos, e os objetivos mútuos (HAKANSSON; SNEHOTA, 1995).
O balanço de forças entre as empresas pode ser compensado por relacionamentos baseados na definição de ganhos conjuntos e de longo prazo, que podem ser acompanhados por meio de variáveis, observadas com freqüência em relacionamentos colaborativos. Apesar de a literatura identificar diversas variáveis utilizadas para acompanhar o desenvolvimento de relacionamentos comerciais (colaborativos ou não), a maioria dos trabalhos encontra dificuldade nesse acompanhamento. Isso ocorre principalmente quando as variáveis observadas não possuem parâmetros quantitativos, como volume de vendas ou de devolução. Assim, é necessário além de definir as variáveis que serão utilizadas para avaliar o relacionamento comercial, estabelecer como essas variáveis serão observadas ou avaliadas.

\section{A definição das variáveis e a construção da matriz}

Diversos autores identificaram, em seus estudos, um grande número de variáveis (formadas por ações e comportamentos adotados pelos funcionários ou pelas próprias empresas, que procuram caracterizar um aspecto da relação comercial) que poderiam ajudar a explicar as atitudes tomadas pelas empresas durante o período em que estas mantivessem um relacionamento colaborativo. Segundo Pressey e Mathews (2000), é clara a falta de consenso sobre quais deveriam ser as variáveis presentes em um relacionamento comercial que o caracterizasse como colaborativo.

A satisfação do cliente foi, por muitos anos, a variável principal para entender as atitudes e as intenções dos clientes. Porém, o deslocamento da literatura de trocas comerciais de um foco meramente transacional para um relacional, ampliou a análise da tomada de decisão do consumidor organizacional, incluindo outras variáveis: qualidade percebida, confiança e compromisso (MACDONALD; SMITH, 2004).

Como muitas das variáveis identificadas na literatura são, na verdade, diferentes denominações para uma mesma variável, optou-se por selecionar apenas 11 variáveis: adaptação, confiança, conflito, cooperação, cultura organizacional, dependência, investimento específico, poder e satisfação (Quadro 1). A escolha deu-se em razão da maior incidência destas nos estudos analisados e do destaque dado a elas nos estudos pioneiros de Dwyer et al. (1987), Anderson e Narus (1990), Mohr e Spekman (1994) e Morgan e Hunt (1994).

Mesmo identificando as 11 variáveis que se sobressaíram na literatura sobre relacionamentos comerciais, mantêm-se o problema de como acompanhar e avaliar o desenvolvimento dessas variáveis nos relacionamentos comerciais existentes dentro de um canal de distribuição. Muitas dessas variáveis não possuem informações 
Quadro 1. Variáveis utilizadas para definir relacionamento.

\begin{tabular}{|c|c|}
\hline Variável & Autores \\
\hline Adaptação & $\begin{array}{l}\text { Wilson (1995); Leonidou e Kaleka (1998); Crotts e Turner (1999); Bennett e Gabriel (2001); } \\
\text { Fynes e Voss (2002). }\end{array}$ \\
\hline Confiança & $\begin{array}{l}\text { Dwyer et al. (1987); Anderson e Narus (1990); Mohr e Spekman (1994); Morgan e Hunt (1994); } \\
\text { Wilson (1995); Kumar (1996); Wilson e Vlosky (1997); Leonidou e Kaleka (1998); Hogarth-Scott (1999); } \\
\text { Crotts e Turner (1999); Bennett e Gabriel (2001); Gadde e Hakansson (2001); Lindgreen (2001); } \\
\text { Fynes e Voss (2002). }\end{array}$ \\
\hline Comunicação & $\begin{array}{l}\text { Mohr e Spekman (1994), Morgan e Hunt (1994), Leonidou e Kaleka (1998), Crotts e Turner (1999), } \\
\text { Pressey e Mathews (2000), Bennett e Gabriel (2001). }\end{array}$ \\
\hline Comprometimento & $\begin{array}{l}\text { Mohr e Spekman (1994), Morgan e Hunt (1994), Wilson (1995), Hogarth-Scott (1999), Leonidou e Kaleka } \\
\text { (1998), Wilson e Vlosky (1998), Crotts e Turner (1999). }\end{array}$ \\
\hline Conflito & Morgan e Hunt (1994); Leonidou e Kaleka (1998); Lindgreen (2001); Gadde e Hakansson (2001). \\
\hline Cooperação & $\begin{array}{l}\text { Mohr e Spekman (1994); Morgan e Hunt (1994); Wilson (1995); Spekman et al. (1997); } \\
\text { Leonidou e Kaleka (1998); Crotts e Turner (1999); Gadde e Hakansson (2001); Lindgreen (2001); } \\
\text { Fynes e Voss (2002); Batt (2003). }\end{array}$ \\
\hline Cultura Organizacional & Denison (1996); Cameron e Quinn (1999); O’Toole (2002); Hatch (2004). \\
\hline Dependência & $\begin{array}{l}\text { Mohr e Spekman (1994); Wilson (1995); Wilson e Vlosky (1997); Leonidou e Kaleka (1998); } \\
\text { Crotts e Turner (1999); Hogarth-Scott (1999); Gadde e Hakansson (2001); Lindgreen (2001); } \\
\text { Fynes e Voss (2002); Batt (2003). }\end{array}$ \\
\hline Investimento Específico & Wilson (1995); Spekman et al. (1997); Crotts e Turner (1999); Bennett e Gabriel (2001); Batt (2003). \\
\hline Poder & $\begin{array}{l}\text { Mohr e Spekman (1994); Wilson e Vlosky (1997); Hogarth-Scott (1999); Crotts e Turner (1999); } \\
\text { Pressey e Mathews (2000); Gadde e Hakansson (2001); Lindgreen (2001); Batt (2003). }\end{array}$ \\
\hline Satisfação & $\begin{array}{l}\text { Wilson (1995); Leonidou e Kaleka (1998); Crotts e Turner (1999); Bennett e Gabriel (2001); } \\
\text { Fynes e Voss (2002); Batt (2003). }\end{array}$ \\
\hline
\end{tabular}

Fonte: Elaborado pelos autores, a partir dos autores citados.

quantitativas que possam ser utilizadas como forma de mensuração, além disso, existe a dificuldade de correlacionar determinados resultados quantitativos, com variáveis de relacionamento.

Para resolver esse problema foram identificados, por meio de revisão teórica, comportamentos adotados por empresas (comerciais e industriais), que estivessem associados a cada uma das variáveis, e ações genéricas que fossem passíveis de serem executadas pelos diversos agentes em seus relacionamentos comerciais (Quadros 2 e 3). Essas ações e comportamentos foram, então, utilizados para desenvolver a matriz de análise, que procura expandir a idéia do continuun de relacionamentos comerciais, auxiliando na classificação dos relacionamentos existentes para, conseqüentemente, poder gerenciá-los de forma mais eficiente. A matriz tem entre seus modelos de apoio, o continuun de Jackson (1985). Apesar de proposto há quase 15 anos, o continuиn ainda serve como fundamento teórico para os modelos de Marketing de Relacionamento. Nele, o autor destaca dois tipos distintos de comportamento de compra no ambiente organizacional. Em um extremo o always-a-share, com relações orientadas para curto prazo, e no outro extremo, o lost-for-good, que se refere a continuidade nas interrelações entre compradores e vendedores (VIANA et al., 1999).

A Figura 1 procura sintetizar o processo de construção da metodologia que gerou a matriz de análise. A

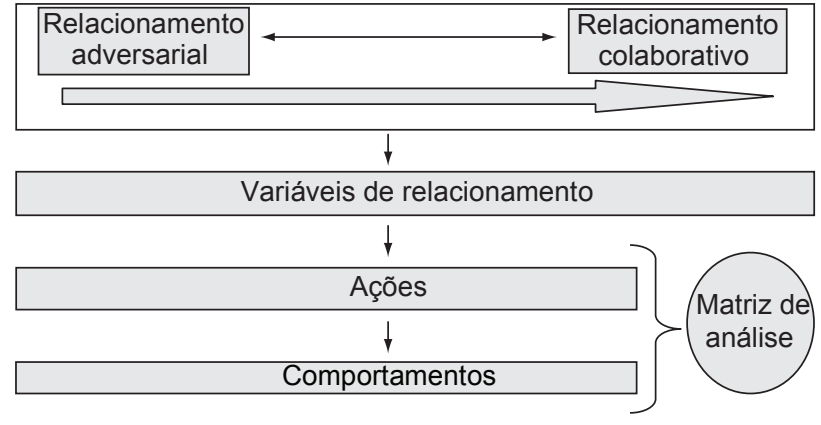

Figura 1. Identificação das variáveis e das ações que determinam a evolução dos relacionamentos comerciais. Fonte: elaborado pelos autores.

partir da identificação das variáveis que descrevem os tipos de comportamento existentes, no continuиm entre um relacionamento adversarial e um relacionamento colaborativo, foram associadas ações e comportamentos que pudessem caracterizar essas variáveis.

As ações e os comportamentos são classificados, conforme seu grau de importância para o relacionamento analisado, por meio de uma escala Likert. A partir dessa classificação, as notas são transformadas em índices que são utilizados para comparar os relacionamentos analisados e são visualizados por meio da matriz.

A matriz de análise (Figura 2) é formada por quadrantes (nível 1, nível 2, nível 3, nível 4), de acordo 
Quadro 2. Padrões de comportamentos por variável estudada.

Confiança

1. A empresa poderia reduzir o número de fornecedores da qual compra e concentrar seus esforços na relação com este fornecedor;

2. A nossa empresa acredita que pode confiar nesse fornecedor, caso precise de ajuda comercial;

3. As transações com este fornecedor não precisam ser supervisionadas detalhadamente;

4. Estamos dispostos a aceitar desvantagens a curto prazo para manter esta relação;

5. Este fornecedor toma decisões unilaterais sem comunicar-nos previamente*;

6. Este relacionamento de troca poderia ser mais bem descrito como uma "série de negócios momentâneos" do que "um planejamento a longo prazo"*;

7. Nós tomamos decisões unilaterais sem comunicarmos previamente este fornecedor*;

8. Nossa empresa compartilha informações com este fornecedor as quais não seriam compartilhadas com outros fornecedores;

9. Nossa empresa encoraja outras empresas a fazerem negócios com este fornecedor; e

10. Nossa relação é administrada principalmente por um acordo informal.

Comprometimento

1. O fornecedor parece mais interessado nos próprios resultados do que nesta relação*;

2. A empresa não compraria de outro fornecedor itens à custa deste fornecedor;

3. As duas partes fazem planos, não apenas com relação a comportamento individual mas, também com relação a continuação da relação;

4. Esperamos aumentar as compras junto a este fornecedor no futuro;

5. Este fornecedor é apenas mais um fornecedor*; e

6. Quando uma situação inesperada surge, preferimos trabalhar uma nova relação (transação), em lugar de procurar segurar o parceiro por meio das condições originais*.

Cooperação e conflito

1. As expectativas sobre o desempenho deste fornecedor relacionam-se ao objetivo imediato da nossa organização*;

2. Nossa equipe de compras trabalha conjuntamente com a equipe de vendas deste fornecedor;

3. A falta da cooperação causou problemas em nosso relacionamento;

4. A falta de queixas por parte do parceiro é um sinal de que estamos trabalhando no sentido de um relacionamento colaborativo; e

5. O desempenho insatisfatório causou problemas em nosso relacionamento.

Satisfação

1. Diferença de opinião entre a empresa e estas fornecedoras serão encaradas como "parte integrante do mundo de negócios" e resultarão em benefícios para ambos;

2. É fácil concordar sobre como assegurar as variáveis que sustentam este relacionamento;

3. Freqüentemente este fornecedor falha nas ações de suporte que deveria oferecer*;

4. Nós fazemos freqüentemente promessas para nosso fornecedor que não conseguimos cumprir*; e

5. Os desacordos entre as duas empresas são raros.

Comunicação

1. A empresa mantém registro do número de reclamações com relação aos produtos desse fornecedor e os repassa;

2. A troca de informação nesta relação ocorre com freqüência e informalmente, e não apenas segundo acordos pré-determinados;

3. A troca de informações com este fornecedor ocorre geralmente nos níveis mais altos da empresa*; e

4. O esforço de comunicação entre a empresa e este fornecedor envolve muitos contatos inter-firmas.

Investimento específico

1. A empresa mantém registros sobre a alteração dos custos dos produtos deste fornecedor;

2. Estamos dispostos a alocar um considerável esforço e investimento no fortalecimento do relacionamento comercial com este fornecedor; e

3. Os investimentos para desenvolver o relacionamento com este fornecedor são facilmente transferíveis para outros processos ou operações em nossa empresa*.

Cultura organizacional

1. A empresa estimula os funcionários a estabelecer contatos pessoais com os funcionários deste fornecedor;

2. A orientação para a parceria demonstrada pelos executivos de ambas as empresas esta relacionada de forma positiva com o desempenho da relação;

3. As percepções dos executivos da nossa empresa e deste fornecedor sobre a parceria são concordantes;

4. É difícil compreender o comportamento e as maneiras do fornecedor pensar*;

5. É difícil fazer amigos com os setores de vendas deste fornecedor*; e

6. Este relacionamento nos fez alterar as funções determinadas para cada departamento da empresa. 
Quadro 2. Continuação...

Cultura organizacional

7. Este relacionamento trouxe maior responsabilidade para o departamento responsável pela logística;

8. Nós designamos um gerente específico para este relacionamento; e

9. Nosso executivo de suprimentos conhece todos os serviços ofertados por este fornecedor.

Adaptação

1. A empresa espera poder fazer ajustes na relação em andamento;

2. Flexibilidade em resposta a pedidos para mudanças é uma característica desta relação;

3. Adaptação Administrativa;

4. Adaptação Logística;

5. Adaptação em Produto; e

6. Adaptação em Processo.

Poder e dependência

1. A relação de troca com este fornecedor criou uma complexa rede de inter-relações entre nós;

2. Abandonar agora a parceria com este fornecedor seria muito difícil, mesmo se quiséssemos fazê-lo;

3. Há muitos fornecedores alternativos para os produtos que nós compramos deste fornecedor;

4. Nós temos valores similares a respeito de como criar valor para o cliente;

5. Seria difícil para este fornecedor substituir as vendas e lucros gerados pela nossa empresa;

6. A empresa é mais importante para este cliente do que ele é para nós;

7. Este fornecedor sabe que, não seria difícil para nossa empresa encontrar outro fornecedor;

8. Nossa empresa possui formas de obrigar este fornecedor a completar a tarefa acordada; e

9. Nossa organização assegura-se que o fornecedor está agindo como nós esperamos monitorando cada transação*.

Os comportamentos assinalados com * significam que a nota possui peso contrário. Quando o entrevistado condicionou uma nota baixa à afirmação, ele estava na verdade discordando dela.

Quadro 3. Ações genéricas por variável estudada.

Confiança

1. Confere as informações passadas pelo fornecedor com outros varejistas;

2. Exigência de relatório assinado por supervisor sobre as transações realizadas;

3. Existência de contrato determinando tarefas de ambas as partes;

4. Mantêm contato com outros fornecedores concorrentes do parceiro; e

5. Redução de estoques.

Comprometimento

1. Agilidade na confirmação do pedido;

2. Indicar pessoas responsáveis e competentes como elo de ligação;

3. Resposta rápida quando surgem problemas;

4. Visitas periódicas do vendedor;

5. Aviso sobre alteração dos custos dos produtos;

6. Manutenção de estoque de segurança;

7. Percentual dos pedidos que resultam em reclamação;

8. Apoio pós-venda; e

9. Aceitar retroca.

Cooperação e conflito

1. Conhecimento da parceria restrito a diretoria;

2. Divisão de responsabilidades na correção de problemas;

3. Estímulo ao contato pessoal e interação entre os funcionários de diferentes departamentos das empresas;

4. Incentivo à interação entre as áreas envolvidas;

5. Incentivo ao questionamento dos fatos;

6. Manutenção de equipes do fornecedor nas lojas;

7. Preço competitivo;

8. Promoções conjuntas; e

9. Recusar-se a participar de promoção; 
Quadro 3. Continuação...

Cooperação e conflito

10. Redução do volume de negócios;

11. Suspensão de todas as compras deste fornecedor;

12. Todas as informações sobre as partes são de conhecimento mútuo; e

13. Todos os funcionários possuem conhecimento sobre o parceiro.

\section{Satisfação}

1. Apoio no merchandising;

2. Percentual dos pedidos que são entregues completos;

3. Tempo de demora entre informação do problema e recuperação da falha;

4. Tempo de espera para o recebimento das pendências;

5. Tempo entre pedido e recebimento do produto; e

6. Uniformidade no volume de compras.

Comunicação

1. Análise conjunta dos dados sobre consumo, compras, retornos;

2. Análise conjunta sobre o número e local dos produtos na gôndola;

3. Distribuição de relatórios relevantes para o parceiro;

4. Estudo sobre as necessidades e desejos dos clientes finais; e

5. Relatórios com as faltas e problemas recorrentes.

Investimento específico

1. Investimento em equipamento/maquinário;

2. Investimento em software;

3. O fornecedor estar aparelhado para conectar os sistemas para recebimento de pedidos e programação do cliente; e

4. Programa de treinamento dos funcionários.

Cultura organizacional

1. Coordenação conjunta do planejamento das atividades;

2. Comunicação entre o departamento de marketing e outras áreas da empresa;

3. Análise conjunta dos funcionários envolvidos na relação;

4. Bom nível do relacionamento entre os funcionários e a administração do fornecedor;

5. Existência de um departamento responsável pelas parcerias;

6. Necessidade de adaptações administrativas; e

7. Prepara do vendedor.

Adaptação

1. Atender a mudanças de prazos, volume, variedade;

2. Atender a pedidos provocados por picos sazonais;

3. Avisar sobre adiamento da entrega;

4. Disponibilizar local e horário especial para descarga;

5. Entregar os produtos em cada estabelecimento (loja);

6. Fazer aviso prévio de entrega;

7. Pedido preparado pelo cliente;

8. Possuir código de barras (na embalagem); e

9. Realizar entrega paletizada.

Poder e dependência

1. Atribuição de descontos associados a rappel;

2. Atribuição de descontos devido à abertura de novas lojas;

3. Atribuição de descontos devido à compra em determinadas épocas;

4. Descontos serem associados ao volume global de compras;

5. Existência de promoções segundo o interesse do varejista;

6. Pagamentos associados à localização dos produtos na loja;

7. Pagamentos de ações promocionais dos distribuidores pelos fabricantes;

8. Prática de "prêmios de entrada em linha";

9. Riscos da transação são assumidos pelos fornecedores;

10. Dificuldade de encontrar outro fornecedor; e

11. Aumento das compras desse fornecedor em detrimento de outros; 
com a evolução dos índices obtidos para as ações desenvolvidas pelas duas empresas e dos índices obtidos pelos comportamentos adotados por essas mesmas empresas (mensurados conforme os Quadros 4 e 5). A matriz permite acompanhar o desenvolvimento de parcerias comerciais tendo como base dois parâmetros, as ações associadas ao relacionamento em questão (ações que podem ser desenvolvidas por uma ou pelas duas empresas do relacionamento), e os comportamentos associados a esses mesmos agentes.

A evolução desses dois índices de maneira conjunta permite verificar se as duas empresas estão buscando atuar de forma colaborativa. Se a evolução for observada em apenas um dos eixos da matriz de análise, é

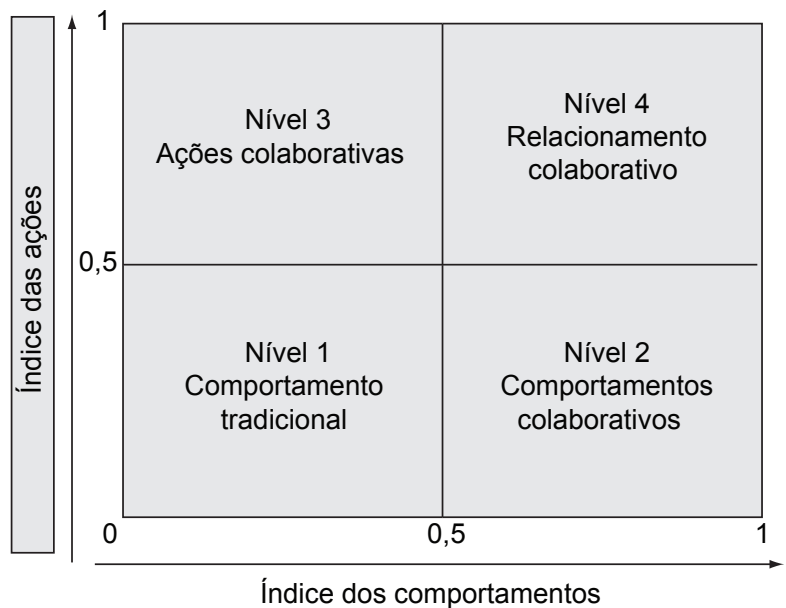

Figura 2. Matriz de análise. possível observar onde estão as oportunidades a serem desenvolvidas pelas empresas, visando à melhoria no relacionamento em desenvolvimento.

Para o cálculo dos índices, existe a necessidade de mensurar as ações e os comportamentos identificados pelos Quadros 2 e 3, porém estes não poderiam ser avaliados por meio de informações quantitativas dado que, em várias situações, tal informação não poderia ser obtida. Como alternativa, decidiu-se pelo uso de escalas Likert para quantificar as ações e os comportamentos das empresas que mantêm relacionamentos colaborativos.

As notas atribuídas aos comportamentos são então formadas por uma escala Likert de 5 pontos (nota 1 significa discordo totalmente da afirmação; nota 2, discordo mais do que concordo; nota 3 , para mim tanto faz; nota 4 , concordo mais do que discordo; e nota 5 , concordo totalmente com a afirmação). Da mesma forma, as notas atribuídas às ações também são formadas por uma Escala Likert de 5 pontos (nota 1 significa sem importância; nota 2 significa pouco importante; nota 3 significa importante; nota 4 significa muito importante; e nota 5 significa imprescindível).

Posteriormente, as notas atribuídas aos comportamentos e às ações são transformadas em índices, um para os comportamentos adotados e outro para as ações realizadas, conforme detalhado pelos Quadros 4 e 5. Os índices das ações e dos comportamentos, variam entre 0 (zero), que significaria um relacionamento completamente adversarial, e 1 (um), que designaria um relacionamento perfeitamente colaborativo.

Para melhor visualizar o grau de colaboração do relacionamento entre duas empresas, optou-se por criar uma

Quadro 4. Formação do índice das ações que formam um relacionamento colaborativo.

Passo 1 - Obter a nota para a ação (cinco é o grau de importância máximo a ser inferido pelos entrevistados)

Passo 2 - Obter a média do grau de importância inferido pelas duas empresas para cada uma das ações observadas

Passo 3 - Dividir o resultado pelo grau máximo permitido (5)

Passo 4 - Resultado é um índice individual para cada ação dos parceiros

Passo 5 - Somar todos os índices individuais de cada ação

Passo 6 - Dividir o resultado da somatória, pelo número total de ações, tendo como resultado o índice para as ações da relação

Quadro 5. Formação do índice de comportamentos que formam um relacionamento colaborativo.

Passo 1 - Obter a nota para o comportamento (cinco é o grau de importância máximo a ser inferido pelos entrevistados);

Passo 2 - Obter a média do grau de importância inferido pelas duas empresas para cada um dos comportamentos observados;

Passo 3 - Dividir o resultado pelo grau máximo permitido (5);

Passo 4 - Resultado é um índice individual para cada comportamento dos parceiros;

Passo 5 - Somar todos os índices individuais de cada comportamento; e

Passo 6 - Dividir o resultado da somatória, pelo número total de comportamentos tendo como resultado o índice para os comportamentos da relação.

No caso dos comportamentos, alguns possuem notas invertidas, ou seja, para designar um relacionamento colaborativo a nota máxima a ser dada é 1. Entretanto, para a formação do índice, as notas não serão invertidas. Como o índice do comportamento é resultado da soma dos índices individuais, empresas que auferiram uma nota 5 (relacionamento adversarial) teriam um resultado maior do que a empresa que auferiu nota 1 (relacionamento colaborativo) para um determinado comportamento. 
classificação em 4 posições, de acordo com o índice das ações e dos comportamentos apresentados pelos pares, resultando na matriz de análise, que pode ser observada na Figura 2. Os 4 níveis utilizados foram: nível 1 (comportamento tradicional), nível 2 (comportamentos colaborativos), nível 3 (ações colaborativas), nível 4 (relacionamento colaborativo), como apresentado a seguir.

Nível 1: Ações e comportamentos realizados pelos pares, com o grau de relacionamento apresentando índices abaixo de 0,5 para os dois parâmetros. Caracterizado como um relacionamento que apresenta comportamentos ainda oportunistas por parte de uma ou das duas empresas que se consideram parceiras, e por ações que determinam a obtenção de resultados vantajosos de curto prazo por um dos parceiros. Os comportamentos e as ações ainda representam objetivos de curto prazo e os resultados não são medidos e avaliados.

Nível 2: Comportamentos com grau de relacionamento apresentando índices acima de 0,5, porém ações com grau de relacionamento apresentando índices abaixo de 0,5 . As empresas podem até desenvolver planejamentos e estabelecer parcerias que demonstrem haver um relacionamento colaborativo. Porém, sem a realização de ações que confirmem essa parceria, por meio da integração dos funcionários responsáveis pelas atividades do dia-adia, o objetivo do relacionamento colaborativo não será atingido. Normalmente, a criação de parcerias é resultado da aproximação dos níveis hierárquicos superiores. Entretanto, se não houver a conscientização dos níveis hierárquicos inferiores, não haverá o desenvolvimento das ações que manterão o relacionamento.

Nível 3: Ações com grau de relacionamento apresentando índices acima de 0,5 , porém, comportamentos com grau de relacionamento apresentando índices abaixo de 0,5. Nesse caso, os comportamentos serão resultado de ações desenvolvidas pelas empresas, ou mesmo, ações desenvolvidas por iniciativa dos vendedores e dos compradores das empresas.

As ações serão realizadas buscando-se atingir não só os objetivos de curto prazo, como lucratividade e participação de mercado, mas também, desenhar comportamentos que podem levar ao crescimento da parceria. Normalmente as ações surgem nos níveis hierárquicos mais baixos, que desenvolvem as ações do dia-a-dia e, conseqüentemente, atingem resultados que passam a chamar a atenção dos níveis superiores. $\mathrm{O}$ posicionamento da parceria no nível 3 significa que as empresas estão se dirigindo para um relacionamento colaborativo, desenvolvendo as ações que terão como resultado comportamentos mais colaborativos.

Nível 4: Ações e comportamentos com o grau de relacionamento apresentando índices acima de 0,5 para os dois parâmetros. Relacionamento considerado colaborativo, com as duas empresas apresentando um comportamento, em que os objetivos conjuntos e de longo prazo se complementam aos objetivos individuais. As ações serão realizadas seguindo um planejamento realizado antecipadamente, no qual as metas e os objetivos já foram definidos. Além disso, as ações são acompanhadas e discutidas conjunta e constantemente.

Esses índices, plotados na matriz de análise, classificam o relacionamento existente entre os parceiros. $\mathrm{O}$ uso da matriz possibilita acompanhar o desenvolvimento de uma relação comercial entre duas empresas. É possível observar a trajetória das ações realizadas e dos comportamentos adotados pelas empresas, a partir de um comportamento tradicional, até as empresas visualizarem os resultados de um comportamento colaborativo.

\section{Aplicação em redes varejistas de pequeno e médio porte}

Buscando testar a matriz de análise, esta foi aplicada em 10 empresas do setor varejista de pequeno e médio porte, localizados no interior do estado de São Paulo, e em 1 fornecedor de mercearia básica de cada uma das redes. As empresas varejistas foram escolhidas de forma dirigida, dentre aquelas que estavam interessadas em relatar suas relações comerciais consideradas mais próximas.

A concentração do estudo em redes localizadas no Estado de São Paulo deve-se a algumas características que destacam o estado: 1) sua importância econômica, como principal mercado consumidor do País; 2) sua localização geográfica em relação aos mercados produtores e demais mercados consumidores; 3 ) a geração de emprego proporcionado por essas redes; e 4) apesar da existência, no Estado, de grandes redes nacionais e internacionais, redes de pequeno e médio porte ainda são responsáveis por parte significativa da venda de mercadorias ao consumidor final.

Com o objetivo de avaliar o uso da matriz, foi solicitada às redes que identificassem um fornecedor considerado parceiro e respondessem a um questionário, compostos dos Quadros 2 e 3, com base na sua relação com este parceiro. $\mathrm{O}$ mesmo foi feito posteriormente com o fornecedor indicado. Os 10 pares analisados responderam ao questionário com base na escala Likert apresentada. Com as notas atribuídas foi possível calcular um índice para as ações e outro para os comportamentos de cada um dos pares analisados, utilizando os passos descritos nos Quadros 4 e 5.

$\mathrm{O}$ resultado mostrou que os 10 pares pesquisados se encontram no quadrante que representa o nível 4, conforme mostra a Figura 3. Apesar de as 10 relações analisadas se encontrarem no quadrante superior (que demonstra um relacionamento colaborativo), não significa que a intensidade da colaboração é a mesma para todos os pares. Analisando-se as 11 variáveis compor- 


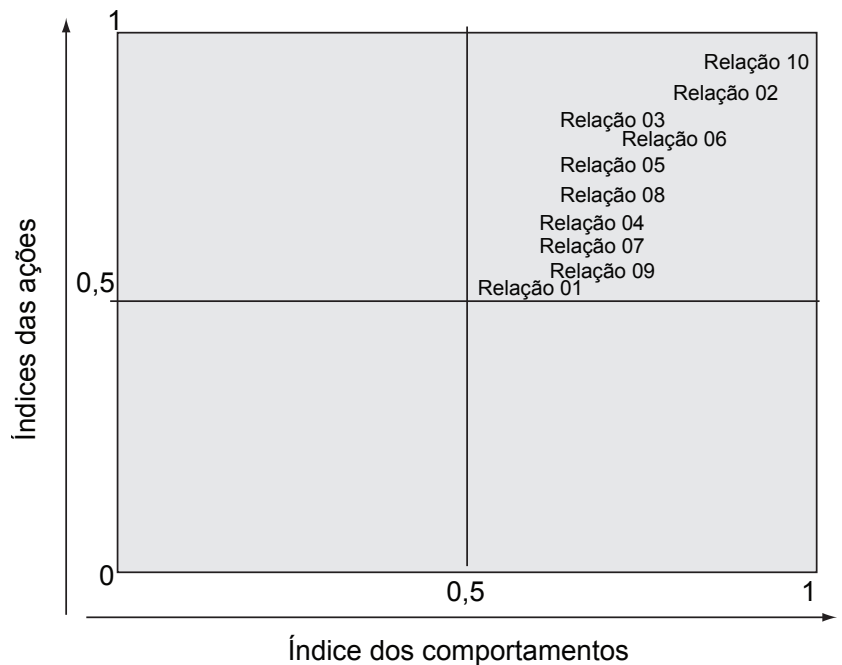

Figura 3. Níveis de relacionamento entre redes varejistas e fornecedores.

tamentais e comparando-as entre os pares analisados, torna-se mais claro as diferenças entre os 10 pares analisados nesse trabalho. Foi possível perceber, por exemplo, que enquanto a relação formada pela rede varejista 10 e o seu fornecedor (que conforme a matriz possui o melhor relacionamento comercial) apresenta os maiores índices em 07 das 11 variáveis comportamentais, a relação formada pela rede varejista 01 e o seu fornecedor, não possui índices significativos em nenhuma das variáveis.

É importante destacar, que a relação comercial que possui o melhor relacionamento, possui os melhores índices justamente nas variáveis comunicação, cultura organizacional, cooperação, e o binômio poder/dependência que são necessárias para gerar a confiança e o comprometimento entre as partes. Dessa forma, é possível perceber que o relacionamento colaborativo entre a rede varejista 10 e o seu fornecedor está sendo construído, por meio de ações e comportamentos, de forma a ser sustentável e com resultados positivos para as duas empresas. $\mathrm{O}$ relacionamento teve origem nas ações desenvolvidas conjuntamente e, com a sua evolução, essas ações foram assumidas por meio dos comportamentos adotados pelos parceiros e, como resultado, as empresas desenvolveram uma relação colaborativa.

Entre as ações que demonstram o grau de colaboração entre essa rede varejista e o fornecedor de mercearia básica, algumas merecem maior destaque: a) das 10 relações estudadas, é a única em que o fornecedor possui um gerente, além do vendedor, que visita todas as lojas da rede para saber se as ações estão sendo desenvolvidas de acordo com o planejado entre as partes, verificar o desempenho dos repositores e promotores da empresa, conversar com clientes da rede varejista e com os funcio- nários desta rede. É função desse gerente, atender e entender a rede varejista; b) apesar de não ser o maior cliente do fornecedor na região, a rede varejista recebe investimentos relevantes do parceiro em função do potencial demonstrando e do perfil do consumidor de suas lojas; e c) são desenvolvidas ações de longo prazo (planejamento conjunto) entre as empresas, e o parceiro é avisado com maior antecedência sobre as ações planejadas por um dos agentes.

Outro relacionamento comercial com bons resultados, segundo os índices de comportamento e de ações que formam a matriz, é o relacionamento mais antigo dos 10 analisados. Consequiência natural do desenvolvimento das relações comerciais entre a rede varejista 02 e o seu fornecedor, o relacionamento teve origem no interesse mútuo das partes, A rede varejista buscava uma marca conhecida na região e o fornecedor buscava novos canais de distribuição que se diferenciassem dos canais até então atendidos pela indústria.

Quando a relação comercial entre as duas empresas se iniciou, a rede varejista estava começando suas atividades em um mercado atrativo, em termos de potencial de consumo. Já o fornecedor, possuía uma marca reconhecida na região e atendia a principal rede varejista da cidade. Hoje a rede varejista tornou-se referência na região, tendo maior reconhecimento que a marca do fornecedor. Essa evolução da rede varejista não alterou a relação de confiança e comprometimento entre as duas empresas. Como o parceiro da rede varejista não é uma multinacional, com recursos para investimentos, a parceria não possui destaque nos índices que formam o comportamento e as ações, porém, possui a segunda melhor média de inferências nos dois parâmetros.

Chama a atenção também o relacionamento entre a rede varejista 06 e o fornecedor. $\mathrm{O}$ fornecedor começou a atender a rede varejista a menos de 2 anos, e mesmo assim, já apresenta resultados significativos (conforme os índices de ações e comportamentos que formam a matriz). A relação não apresenta os maiores índices de comportamento em nenhuma das 11 variáveis comportamentais, por outro lado, a relação possui o melhor desempenho em 6 índices de ações, desempenho superior inclusive ao da relação envolvendo a rede varejista 10. Esse resultado corrobora o modelo, que determina que uma relação colaborativa se desenvolva inicialmente com ações colaborativas entre as redes e, a partir dessas ações, os comportamentos se desenvolvam naturalmente.

As relações que se apresentam na seqüência, não possuem destaque em nenhum dos grupos de ações que formam um dos parâmetros de análise. Entre os comportamentos, todas possuem bons índices. Isso significa que existe um grande interesse por parte dessas empresas em criar relacionamentos colaborativos, entretanto, não 
estão conseguindo transformar o interesse em ações que possam realmente se converter em benefícios conjuntos.

Percebe-se, nesses relacionamentos, uma baixa participação dos demais membros envolvidos no relacionamento comercial (relação restrita aos compradores, vendedores e, em alguns casos, diretores), a troca de informações ainda é incipiente, assim como as adaptações que envolvem o relacionamento e a cultura organizacional das empresas.

No caso das empresas que apresentaram baixos índices com relação ao parâmetro comportamento e ao parâmetro ações, esses índices são resultado de uma série de fatores que em seu conjunto levam a rede a ter um relacionamento colaborativo abaixo das expectativas de ambas as partes. A baixa troca de informações e a falta de confiança em disponibilizar as informações para o parceiro, talvez sejam os fatores que determinam o resultado da relação. O baixo índice obtido no parâmetro que representa as ações comprova que o caminho de colaboração que está sendo desenvolvido pelos parceiros, não está levando aos resultados esperados.

\section{Conclusão}

Conhecendo os comportamentos e as ações que caracterizam um relacionamento comercial, os parceiros podem identificar os pontos em que o relacionamento não atende aos objetivos desejados, buscando conhecer as causas da não obtenção dos resultados e formas de aproveitar a oportunidade para aprofundar a relação.

Uma consequiência natural do desenvolvimento dessas relações é que o aumento da competitividade e da geração de resultados de uma empresa torna-se altamente dependente das habilidades de seus parceiros. Dessa forma, por exemplo, as alterações observadas nas estratégias dos agentes (fornecedores e distribuidores) que formam um canal de distribuição, estão promovendo alterações importantes na arquitetura de muitos desses canais. Esses estão revendo suas fronteiras e formas de atuação, levando a mudança nas competências e modificando a forma de relacionamento com seus fornecedores.

Entretanto, é necessário saber como essa relação é vista e analisada pelos parceiros. Para isso, por meio dos comportamentos e das ações dos parceiros, é possível determinar o grau de relacionamento entre os pares. $\mathrm{O}$ grau de relacionamento entre duas empresas permite observar se os comportamentos adotados pelas empresas e as ações desenvolvidas pelos agentes estão atingindo objetivos, que irão resultar em benefícios de longo prazo. Para visualizar e acompanhar o desenvolvimento dos comportamentos e das ações foi desenvolvido uma matriz de análise. Por intermédio dessa matriz, as empresas podem observar os pontos (comportamentos e ações) em que o relacionamento está avançando e os pontos nos quais ainda existem oportunidades de o relacionamento ser melhorado.

Classificando as ações e os comportamentos, é possível determinar o grau de colaboração presente no relacionamento. O grau de colaboração pode ser resultado: a) das ações desenvolvidas pelas empresas (e dessa forma é possível prever uma melhoria no comportamento colaborador das partes); b) dos comportamentos adotados pelas empresas, porém, sem ações que permitam que esses comportamentos se consolidem; c) das ações e comportamentos colaborativos, de forma que os objetivos traçados pelos parceiros possam ser atingidos; e d) da inexistência de ações e comportamentos, que levam o relacionamento a ter características mais próximas de um relacionamento comercial tradicional.

A diferença do grau de colaboração, por exemplo, entre distribuidores e fornecedores em um mesmo canal de distribuição, pode ser ocasionada pela estrutura das empresas, pelo interesse que o fornecedor possui em relação ao distribuidor, pelas ações realizadas pelos parceiros e pelas pessoas responsáveis pela relação. Assim, torna-se importante identificar o grau de relacionamento colaborativo existente entre as empresas, com o objetivo de buscar novas oportunidades naqueles relacionamentos cuja colaboração é mais "evidente", buscar corrigir as pendências nos relacionamentos ainda com deficiências, e indicar ações e comportamentos que possam ser utilizados por essas empresas, ou terceiras, que queiram buscar uma maior aproximação com um parceiro comercial.

A principal barreira identificada em um relacionamento comercial, colaborativo ou adversarial, está justamente na falta de avaliação dos resultados dos relacionamentos. A avaliação realizada pela maioria dos parceiros é referente à evolução financeira e ao volume das vendas dos produtos. Avaliação baseada nos comportamentos e nas ações que determinam os relacionamentos colaborativos ainda é incipiente na grande maioria das empresas. Se a barreira está na quase inexistência de formas de avaliação do relacionamento, o grande fator facilitador está justamente no interesse dessas empresas em avaliar seus relacionamentos e buscar padrões para desenvolver novas ações com outras empresas e comparar esse relacionamento colaborativo com os tradicionais. 


\title{
Distribution channel relationship: a proposal of an analysis matrix
}

\begin{abstract}
Today's market is growing so active and turbulent that a company's ability of developing and managing its relationship with other companies has become a necessary qualification, and if it is well developed, it may become a source of sustainable competitive advantage. Accordingly, the suppliers have been trying to adjust to the increasing power of retailers, to the expansion of horizontal alliance among retailers, to the strengthening of independent retailers, and to all the other kinds of distribution channels. Nevertheless, these companies still find it difficult to follow and assess these commercial relationships and, consequently, to adapt them to this new reality. Thus, the objective of this study is to propose an analysis matrix to assess the relationship among companies by following the behavior and actions of these companies. From an extensive theoretical revision, it was possible to identify variables influencing commercial relationships such as reliability, compromising, interdependence, cooperation, as well as behavior and actions related to each of these variables. This matrix was developed by presuming that the presence of one or more of these variables should mean the possibility of different standards of arrangements among the companies, from the opportunist to the most active collaborator, by using behavior and actions to determine its occurrence. The matrix consists of four categories that can be used to identify the relationship between two companies within four pre-established levels: traditional behavior, collaborative behavior, collaborative actions, and collaborative relationship. After its theoretical development, the matrix was then tested initially for ten pairs of companies, supermarket chains located in the province of São Paulo state and one of their suppliers. The result obtained shows that by assessing the behavior and actions of the partners, it is possible to determine the kind of relationship existing between the pairs studied helping the companies to determine their approaches aiming to improve this relationship or even to end it when necessary.
\end{abstract}

Keywords: Distribution channels. Collaborative relationship evaluated.

\section{Referências bibliográficas}

ANDERSON, J. C.; NARUS, J. A. A model of distribution firm and manufacturer firm working partnerships. Journal of Marketing, Chicago, v. 54, n. 1, p. 42-58, jan. 1990.

BATT, P. J. Building trust between growers and market agents. Supply chain management: An International Journal, Bradford, v. 8, n. 1, p. 65-78, 2003.

BENNETT, R.; GABRIEL, H. Reputation, trust and supplier commitment: the case of shipping company/seaport relations. Journal of business \& industrial marketing, Bradford, v. 16, n. 6, p. 424-438, 2001.

BLACKWELL, R. D. Da criação ao mercado: reinventando a cadeia de suprimento do varejo. São Paulo: Campus, 2001, $264 \mathrm{p}$.

CAMERON, K. S.; QUINN, R. E. Diagnosing and changing organizational culture. Reading, MA: Addison Wesley Longman, 1999. $160 \mathrm{p}$.

CHEN, I. J.; PAULRAJ, A.; LADO, A. A. Strategic purchasing, supply management, and firm performance. Journal of operations management, Atlanta, v. 22, n. 5, p. 505-523, aug. 2004.

COUGHLAN, A. T. et al. Canais de marketing e distribuição. 6. ed. Porto Alegre: Bookman, 2002, 461 p.

CROTTS, J. C.; TURNER, G. B. Determinants of intra-firm trust in buyer-seller relationships in the international travel trade. International journal of contemporary hospitality management, Bradford, v. 11, n. 2/3, p. 116-123, 1999.

DENISON, D. R. What is the difference between organizational culture and organizational climate? A native's point of view on a decade of paradigm wars. The Academy of Management Review. v. 21, n. 3, p. 619-654, jul. 1996
DWYER, F. R.; SCHURR, P. H; OH, S. Developing buyer-seller relationships. Journal of marketing, Chicago, v. 51, n. 2, p. 11-27, apr. 1987.

FYNES, B.; VOSS, C. The moderating effect of buyer-supplier relationshipsonquality practices and performance. International journal of operations \& production management, Bradford, v. 22, n. 6, p. 589-613, 2002.

GADDE, L.; HAKANSSON, H. Supply network strategies. West Sussex: John Willey \& Sons Ltd, 2001.

HAKANSSON, H.; SNEHOTA, I. The burden of relationship or who's next. In: NAUDÉ, P.; TURNBULL, P. W. Network dynamics in international marketing. Oxford: Pergamon, 1998, p. 26-41.

HATCH, M. J. Dynamics in organizational culture. In: POOLE, M. S.; VEN, A. VAN de (eds.) New direction in the study of organizational change and innovation processes. New York: Oxford University Press, 2004. Disponível em: http:// www.commerce.virginia.edu/faculty_research/Research/ Papers/Hatch_Dynamics_Organizational_Culture.pdf. Acesso em: 2004.

HOGARTH-SCOTT, S. Retailer-supplier partnerships: hostages to fortune or the way forward for the millennium? British food journal, Bradford, v. 101, n. 9, p. 668-682, 1999.

JACKSON, B. B. Winning and keeping industrial customers. Lexington: Lexingtons Books, 1985. 195p.

KUMAR, N. The power of trust in manufacturer-retailer relationships. Harvard business review, v. 74, n. 6, p. 92-106, nov./dec.1996.

LEONIDOU, L. C.; KALEKA, A. A. Behavioural aspects of international buyer-seller relationships: their association 
with export involvement. International marketing review, Bradford, v. 15, n. 5, p. 373-397, 1998.

LINDGREEN, A. A framework for studying relationship marketing dyads. Qualitative market research: an international journal, Bradford, v. 4, n. 2, p. 75-87, 2001.

MAcDONALD, J. B.; SMITH, K. The effects of technologymediated communication on industrial buyer behavior, Industrial marketing management, Atlanta, v. 33, n. 2, p. 107-116, feb. 2004.

MOHR, J.; SPEKMAN, R. Characteristics of partnership success: partnership attributes, communication behavior and conflict resolution techniques. Strategic management journal, Hoboken, v. 15, n. 2, p. 135-152, feb. 1994.

MORGAN, R. M.; HUNT, S. D. The commitment-trust theory of relationship marketing. Journal of marketing, Chicago, v. 58, n. 3, p. 20-38, jul. 1994.

O'TOOLE, T. The relationship between employees' perceptions of safety and organizational culture. Journal of safety research, Itasca, v. 33, n. 2, p. 231-243, Summer, 2002.

PRESSEY, A. D.; MATHEWS, B. P. Barriers to relationship marketing in consumer retailing. Journal of services marketing, Bradford, v. 14, n. 3, p. 272-286, jun. 2000.
RITTER, T.; WILKINSON, I.; JOHNTON, W. Managing in complex business networks. Industrial marketing management, Atlanta, v. 33, n. 3, p. 175-183, apr. 2004.

SOUZA, W. Os bons resultados do setor. SuperHiper, São Paulo, ano 31 , n. 353, p. 26-35, maio 2005.

SPEKMAN, R. E.; SALMOND, D. J.; LAMBE, C. J. Consensus and collaboration: norm-regulated behaviour in industrial marketing relationships. European journal of marketing, Bradford, v. 31, n. 11/12, p. 832-856, dec. 1997.

VIANA, D. A.; CUNHA JÚNIOR, M. V. M.; SLONGO, L. A. Medindo o conceito de marketing de relacionamento no contexto brasileiro. In: ENCONTRO NACIONAL DOS PROGRAMAS DE PÓS-GRADUAÇÃO EM ADMINISTRAÇÃO, 19., Foz do Iguaçu, Anais... Foz do Iguaçu, 1999.

WILSON, D. T. An integrated model of buyer-seller relationships. Journal of the academy of marketing science, Georgia, v. 23, n. 4, p. 335-345, sep. 1995.

WILSON, E.; VLOSKY, R. Partnering relationship activities: building theory from case study research. Journal of business research, Amsterdam, v. 39, n. 1, p. 59-70, may 1997.

\section{Sobre os autores}

\section{Gessuir Pigatto}

Centro de Estudos e Pesquisas em Administração de Empresas e Agronegócios - CEPEAGRO,

Departamento de Administração, Universidade Estadual Paulista Júlio de Mesquita Filho - UNESP,

Campus Experimental de Tupã, Avenida Domingos da Costa Lopes, 780, Jardim Unesp, CEP 17602-660, Tupã, SP, Brasil,

e-mail: pigatto@tupa.unesp.br

\section{Rosane Lucia Chicarelli Alcantara}

Grupo de Estudos e Pesquisas Agroindustriais - GEPAI,

Centro de Ciências Exatas e de Tecnologia, Departamento de Engenharia de Produção, Universidade Federal de São Carlos - UFSCar, Rodovia Washington Luiz, Km 235, Jardim Guanabara, CP 676, CEP 13565-905, São Carlos, SP, Brasil,

e-mail: rosane@power.ufscar.br

Agradecimentos: Os autores agradecem ao Conselho Nacional de Desenvolvimento Científico e Tecnológico (CNPq) que financiou a pesquisa que deu origem a este artigo. 
